\title{
Syntax and discourse in Old English and Middle English word order
}

\author{
Ans van Kemenade \& Tanja Milicev \\ University of Nijmegen \& University of Novi Sad
}

In this article, we present an analysis of Old and Middle English word order in which discourse strategies are incorporated into a restrictive syntactic analysis. Building on recent work on clause structure in general, especially Rizzi (1997), Nilsen (2003), and Old and Middle English clause structure in particular, especially van Kemenade (2000; 2002); Biberauer and Roberts (forthcoming), we propose an analysis of Old English clause structure which formulates a number of ways in which discourse strategies are mapped with available syntactic options. In this analysis, clause-internal temporal adverbs such as $p a$ and ponne play a special role. We argue that these adverbs (which we take to be the most representative members of a larger set) act as focus particles which serve to mark the boundary between topic and focus material in the clause. The topic part of the clause will be analysed in the discourse terms inherent in Rizzi's (1997) clausal architecture, which we will, however, reformulate in the spirit of Nilsen (2003). The focus part of the clause is taken to be the (extended) VP-domain.

We will concentrate on subclauses, for familiar reasons: this is the syntactic environment in which we can most readily abstract away from the well-known asymmetries between root vs. nonroot clauses in Old English. We formulate the conditions that elements should satisfy to license their appearance in the topic part of the clause, as well as the discourse effects that they thus produce. While the topic part of the clause may be quite elaborate in Old English, one default option, as determined at that stage by discourse principles, is a word order in which a definite/specific DP-subject alone precedes the focus particle.

The transition to Middle English is marked (in the subclause) by the elimination of the multiple topics that are allowed in Old English. In other words, the word order in which a definite/specific DP subject alone precedes the focus particle, is reanalysed as a grammatical requirement rather than a discourse option. Causes that will be suggested for this reanalysis are the complete breakdown of the relation between case, aspect and definiteness that is characteristic of early Germanic, and the fact that hypotaxis scored a final victory over parataxis, leading to a restructuring of the left periphery of the subclause. The result of this was that embedded clauses totally eliminated their previously relatively complex topic domain, and became categorically subject-initial.

\section{1. the problem in Old English}

There is a growing literature on the pivotal position of adverbs in the clausal structure. (general references Lingua which include work by Alexiadou, Cinque, Ernst, Nilsen, xxxx; for work on the history of English, see van Kemenade 2000; 2002); van Bergen 2000; Haeberli 2000; Haeberli and Ingham 2004). Some firm observations emerge from this work with respect to early English, one of the main ones being that, for a particular class of short, "high" adverbs, pronominal subjects precede these adverbs, whereasDP subjects follow them.

The class of adverbs involved is a slightly elusive one, as it includes temporal adverbs such as $p a, n u$, ponne; the interjection la (Kato 1995); reinforcing negative adverbs, eac 'also' and some others. And even if we limit ourselves to the most consistently behaving adverbs within this class, which are undoubtedly $p a$ and ponne, the word order patterns emerging are not consistent enough to warrant an account in purely syntactic terms. 
For the moment, we limit the discussion to subclauses, for wellknown reasons: subclauses abstract away at least to a large extent from one factor that confuses the surface patterns, namely finite verb placement. Let us look, then, at some examples of the generalizations that have been attempted so far. Van Kemenade $(2000 ; 2002)$ claims (largely based on root clauses), that in clauses with reinforcing negators, and the adverbs $p a$ and ponne, pronominal subjects occur on the left of the adverb, while DP subjects occur on the right. This is illustrated well by the following examples:

Pronominal subject preceding ponne

(1) peah pe he pa fremminge forðbringan ne mihte. (coaelive, ÆLS_[Martin]:746.6442) though that he the performance forth-bring not-could 'although he could not bring forth the performance thereof'

Nominal subject following ponne

(2) Gif him ponne God ryhtlice \& straeclice deman wile. (cocura, CP.5.45.20) if him then God justly and strictly judge will 'if God will then judge him justly and strictly'

Van Kemenade 2002 shows that this generalization holds extremely well for main clause questions. Here are the statistics for ponne in main clause questions in one text, King Alfred's translation of Cura Pastoralis.

\begin{tabular}{|l|l|l|}
\hline & Nominal subject & Personal pronoun subject or object \\
\hline subject left of ðonne & 0 & 10 \\
\hline subject right of ðonne & 17 & 0 \\
\hline
\end{tabular}

Table 1: Root questions: order of subject and ðonne in Cura Pastoralis

In van Kemenade's account, the analysis for the positional discrepancy between pronominal and DP subjects would be that all subjects must be licensed for nominative case in Spec, TP. In addition, pronouns must move to a higher position because they are deficient in the sense of Cardinaletti and Starke (1999). Van Kemenade (2002) does not look specifically at the behaviour of $p a$ and ponne in subclauses. Haeberli and Ingham (2003) look at adverbs more generally in main clauses as well as in subclauses in the earliest period of Middle English in the PPCME corpus (up to AD 1250) and observe that van Kemenade's (2000) analysis is only suited to root clauses. Their basic observation is that in their period, DP subjects in subclauses precede the adverb position quite frequently. On that basis they suggest an analysis in which the position of the adverb is lower than that postulated by van Kemenade. Such an analysis faces a similar problem of having to show why alternative options are allowed as well. Rather than going into the comparative nitty gritty of the various analyses, we wish to pursue a different line of analysis in this article, in order to clear some ground toward a view of Old English clause structure in which syntactic factors are mapped with discourse preferences. Such an analysis entails that the number of word order options allowed, although syntactically constrained, is more liberal than the number usually envisaged in syntactic analyses.

Before we come back to this point, let us first take a closer look at our adverbs. We restrict the discussion to two adverbs: $p a$ and ponne. These adverbs are both basically temporal in meaning and indeed are often used literally as a temporal adverb. However, they also very often used like rhetorical devices, often (for instance in religious texts) in contexts where people are admonished or exhorted. An example of this is the following from Cura Pastoralis: 
(3) Gif ðonne se sacerd bið ungerad ðæs lareowdomes, hwæt forstent ðonne his gehlyd? (cocura, CP, 15,91,25)

if then the teacher is unskilled in instruction, what avails then his cry?

'if the teacher, then, is unskilled in teaching, what avails his cry?'

A further reason for taking these two adverbs is that their behaviour is the most consistent, and therefore they serve as a useful starting point and benchmark for looking at more complex cases at a later stage.

To get a comprehensive picture of the basic facts, we searched for instances of clause-internal $p a$ and ponne in the complete York Corpus of Old English (Taylor et al 2003), excluding the use of $p a$ and ponne as a complementizer, or as a main clause introducer. Examples are discussed below.

\begin{tabular}{|l|l|}
\hline & Nonroot clauses \\
\hline DP subject follows pa/ponne & 419 \\
\hline DPsubject precedes pa/ponne & 293 \\
\hline
\end{tabular}

Table 2 Pa/ponne and DP subject in Old English

\begin{tabular}{|l|c|}
\hline & Nonroot clauses \\
\hline Pro subject preceding $\mathrm{pa} /$ /ponne & 1250 \\
\hline Pro subject following $\mathrm{pa} /$ ponne & 5 \\
\hline
\end{tabular}

Table 3 Da/ponne and pronominal subject in Old English

In subclauses then, the pronominal subject near-categorically precedes $p a /$ ponne as in Table 3 , whereas the DP subject is much more variable in its positioning with respect to the adverb as is evident from Table 2 . Any attempt to analyse this state of affairs in purely syntactic terms on the null assumption that the position of $p a /$ ponne is fixed, should address this variability of the DP-subject and account for the option of two different types of subject positions on the left of the adverb, assuming as is widely accepted that personal pronouns are in a special position anyway.

Pronominal objects may also appear in a position preceding the adverb. Here are the figures, which include two basic patterns: one in which an object pronoun precedes $\mathrm{ba/ponne}$ while a DP subject may follow the adverb, and another in which a subject pronoun and an object pronoun together precede $\mathrm{pa} /$ /ponne. There is a total of 234 cases in which an object pronoun precedes pa/ponne, which includes 95 cases of conjoined subject deletion, relatives with a subject gap, and empty expletives, leaving 129 examples.

\begin{tabular}{|l|l|}
\hline & Nonroot clauses \\
\hline Pro obj - pa/ponne-DP-subj & 39 \\
\hline Pro obj - DP-subj - pa/ponne & $14^{1}$ \\
\hline Pro subj - pro obj - pa/ponne & 74 \\
\hline DP subj - pro obj - pa/ponne & $12^{2}$ \\
\hline Total pro object - pa/ponne & 129 \\
\hline Pro object follows pa/ponne & 86 \\
\hline
\end{tabular}

Table 4: pa/ponne and pro object in Old English

\footnotetext{
${ }^{1}$ This includes 6 cases where the subject is man; we will come back to this below.

2 This includes 1 case in which the subject is man, about which more below.
} 
One crucial question we need to address then is why, in spite of the null option that the position of $\mathrm{pa}$ /ponne seems to be a fixed one, the position of the DP-subject is so variable. The line of argument we pursue in this article is as follows: we maintain the null option that the position of the adverb is fixed, and try to pinpoint the discourse use of $p a /$ ponne. Our hypothesis is that adverbs like $p a /$ /bonne are focus particles that separate the topic part of the clause from the focus part. We note that the notions 'topic' and 'focus' here differ from the ones routinely assumed in formal syntactic analyses, in which a topic is taken to be some constituent moved to Spec,CP. Our notion of topic here is a discourse-oriented one and corresponds roughly with, on the one hand, the material that refers back to referents in the discourse (continued topics), and, on the other hand, the material marking switch or contrast in discourse). This may include various types of subjects and objects, as we will detail below. If this analysis is reasonable, it would indicate that Old English is like discourseconfigurational languages in the sense identified in Kiss (1995). The transition to a later stage would then involve a shift to an organization in more strictly syntactic terms. We first outline a theoretical perspective with which we propose to analyse this set of facts.

\section{Theoretical underpinnings}

Our analysis essentially builds on Nilsen's (2003) approach to structure building, where dynamic interpretations of topic and focus are seen as being able to trigger movement operations required to derive ordering patterns. In this approach, it is not necessary to assume the existence of particular functional projections in the left periphery, such as Topic Phrase and Focus Phrase (cf. Rizzi 1997), the head of which would establish an agreement relation with the element moved to its specifier, providing it with the appropriate interpretation. Eliminating the need for the existence of certain formal, uninterpretable features that would drive each movement operation, it is possible for several operations to be triggered in order to satisfy one interface condition.

More specifically, we follow Nilsen's assumption that the left periphery in Germanic languages is marked by the presence of the so-called Sigma Phrase $(\Sigma \mathrm{P})$, which is associated with topic-hood; it is merged below certain sentential adverbs and undergoes obligatory fronting across the adverb. Being the locus of 'topic' material, any focused material must move out of the scope of $\Sigma$ prior to its preposing. Focus here should be understood as the most informative and 'new' part of the utterance.

The specifier of $\Sigma$ must always be visible due to the presence of an EPP-kind of feature. For the present purposes, we will abstract away from the material associated with the head $\Sigma$, i.e. the attraction of the verb to $\Sigma^{\circ}$, mostly because OE is not an asymmetric V2 language, and the interaction of the finite verb with topic/focus material is not exactly straightforward. Therefore, we will concentrate on the material found in the specifier position of $\Sigma \mathrm{P}$, leaving the question of the position of the verb and the status of focus material for later research.

Nilsen (2003) distinguishes two types of $\Sigma^{\circ}$, modulo the content of the specifier: marked and unmarked. Unmarked $\Sigma$ takes subjects and certain adverbs as its specifier, depending on whether $\Sigma \mathrm{P}$ is merged above or below the subject, while the specifier of the marked $\Sigma \mathrm{P}$ always conveys the meaning of contrastiveness, i.e. it is interpreted as a switch topic. Although we follow Nilsen's in that the Germanic $\Sigma$ is associated with topichood, we depart from his assumption that it can host only topic switchers or switch topics. In our analysis, all topic-like elements can be attracted by $\Sigma$, so as to include continued topics as well. With this approximation, our approach enables us to cover the distribution of weak pronouns in the $\Sigma$ P area, and their interaction with DP subjects which we will show is governed by their discourse status. It also provides a perspective on the relative lack of 
consistency in subclauses: while in Old English many subclauses are of course simply subject-initial and indicative of various possible syntactic analyses so far proposed (see above), we will discuss evidence that suggests a more complex picture. We surmise that this more complex picture is a relic of parataxis in the sense that subclauses show the vestiges of a a rather articulated topic domain more readily associated with main clauses. As hypotaxis, and its morphosyntactic marking, becomes more firmly entrenched, this topic domain is simplified, modulo interaction with other, independent, changes.

To show that the syntactic configuration in $\mathrm{OE}$ is affected by discourse factors, we will focus on the interaction of topic/focus material with our two particular adverbs $p a$ and ponne, and propose that such adverbs are best analyzed as discourse operators, separating the topic/presuppositional from the focus/new information area of the clause. There are two possible ways to derive this. One is to assume that, after the merging of the focus particle, $\Sigma \mathrm{P}$ must move out of its scope, resulting in $\Sigma \mathrm{P}$ - pa/ponne ordering.

$$
\left[\text { FPTP } [ \Sigma \mathrm { P } ] \text { focus prt } \left[\mathrm { FOCUS } \left[\mathbf{t}_{\Sigma \mathrm{P}}[\mathrm{VP} \ldots\right.\right.\right.
$$

The second option is along Nilsen's (2003) analysis of the Norwegian focus particle bare 'only', in which he adopts Kayne's (1998) structure for the focus particle 'only', and proposes that the "focus" adverbs attract the focus material into their specifier, which is followed by merging of the head $\mathrm{W}$, where Topic $\mathrm{P} / \Sigma \mathrm{P}$ subsequently move, together with the adverb.

$$
\left[w P [ \Sigma P ] \text { fpt } \left[\text { FPTP FOCUS } \mathbf { t } _ { \text { fpt } } \left[\mathbf { t } _ { \mathrm { FOCUS } } \left[\mathbf{t}_{\mathrm{LP}}[\mathrm{VP} \cdots\right.\right.\right.\right.
$$

For the purpose of descriptive clarity, we will assume the former option, not excluding the possibility that the more complex second option will prove to be more relevant when the interaction of other adverbs with $\Sigma \mathrm{P}$ on the one hand, and the focus particle on the other, are taken into consideration. With these assumptions in mind, let us consider the properties of various types of material that can occur in $\Sigma$ P.

\section{The content of $\Sigma P$ in Old English}

\subsection{Pronouns in $\Sigma \mathbf{P}$}

Personal pronouns are typical $\Sigma \mathrm{P}$ material. The reason is that pronouns, as (discourse) anaphoric elements, are presuppositional and most readily construed as (continued) topics. Generally, they are found in the highest position in the clause, immediately following the complementizer and preceding pa/ponne. Although pronouns often form a cluster, as in (6), an object pronoun, usually the indirect object, can be found separated from other pronouns. We will discuss those cases later.

(6) gif he hit him ðonne sellan mæge. (cocura, CP.44.323.24)

if he it him then grant may

'if we can give it him then'

When found in $\Sigma \mathrm{P}$, pronominal subjects are categorically found to the immediate right of the complementizer.

$$
\mathrm{CP}[[\Sigma \mathrm{P} \text { Su-pron }] \quad \text { pa/ponne }]
$$


Pronominal objects show a distribution that is slightly more variable. In most cases (39 out of 53 as in Table 4), the object pronoun is found alone in $\Sigma$ P, with the DP subject following the adverb.

( 8)a swa us ponne God mihte sylle. (cochdrul,ChrodR_1:34.1.509)

as us then God might give

'as God might then give us.'

b gif hine ðonne ðæt fleah mid ealle ofergæð, ðonne ne mæg he noht geseon. (cocura,CP:11.69.17.448)

if him then the albugo with all covers, then not-can he naught see

'if it [the pupil of the eye] is entirely covered with albugo, he cannot see anything.'

However, object pronouns can also occur in the high position together with DPsubjects. We saw in Table 4 that in such cases, personal pronoun objects may either precede or follow the DP subject.

(9)a [[sP Su-DP Obj-pro ] pa/ponne $]$

b [[гр Obj-pron Su-Ind/Dem] pa/ponne $][$

As far as their distribution with the DP subject is concerned, OE pronominal objects pattern with other Westgermanic languages, especially German, where deficient/weak pronouns can be found both to the left and the right of a DP subject. The deficient status of the OE pronouns following the DP object is well-supported by the fact that inanimate pronouns are allowed to occur after the DP subject, as in (10).

(10) Swa eac se mona, swa miclum he lyht swa sio sunne hine gescinð (coboeth,Bo:34.86.7.1645)

so also the moon, so-as greatly he makes-light so-as that sun him illuminates 'and also the moon, it lightens the more the sun shines on it'

Since the core semantic requirement on non-deficient pronouns is animacy, this excludes the analysis of such "lower" instances as strong pronouns. One way to account for this distribution is to assume that Germanic weak pronouns have to occur in the highest position in the clause, immediately following the complementizer, due to their status as LF clitics (cf. Grohmann 1997, Laenzlinger \& Shlonsky 1997, Laenzlinger 1998, although the last two differ from what is assumed in Grohmann and here, in that these authors deny the tripartite division of pronouns, i.e. the division of deficient elements into clitic and weak as in Cardinaletti and Starke 1999). We believe that the clitic-type analysis of high pronouns is on the right track, mainly because it captures one of the properties of clitic pronouns that seems to be relevant for the distribution of OE weak pronouns: clitics must have a referent prominent in the discourse (cf. Cardinaletti and Starke 1999). It follows that pronouns surface in non-clitic positions when their referent is not prominent in the discourse. The question now is what decreases the discourse prominence of the referent of the pronoun.

When we look at the broader discourse context of the DP subject - pronominal objectpa/ponne sequences, they are always found when the discourse context conveys the notion of contrastiveness. We believe that 'contrast(iveness)' is always associated with a discourse shift: in order for something to be perceived and subsequently structurally marked as prominent in the discourse (i.e. cliticized), the discourse itself has to be continuous and uninterrupted. Topic switches break the continuity and unity of discourse and in such cases 
high/clitic-type of pronouns are out of place since no immediate connection to the referent of pronoun is intended in the first place. Let us some examples to see how this works:

(11) Gif ðære fæmnan fæder hie [ðonne] sellan nelle, agife he ðæt feoh æfter pam weotuman (colawafint,LawAfEl:29.78)

if that maid father her then give not-will, give he the cattle after the dowry. 'If the woman's father will then not give her in marriage, he shall give her cattle proportionate to the dowry'

Our prediction is that the pronoun follows the subject due to a discourse shift that renders the referent of the pronoun "hie" less prominent than required for a high/clitic pronoun. If we take a look at the previous line, we see that this condition is indeed met. In (12), the line with a low pronoun expresses a shift to a new situation which is in contrast to the previous line (cf. the negative form of the verb, sellan nelle, which is in contrast with the verb forgieldan in the previous line).

(12) Gif hwa fæmnan beswice unbeweddode \& hire mid slæpe, forgielde hie and hæbbe hie him to wife (colawafint,LawAfEl:29.76)

if anyone maid deceive unmarried and her with sleep, pay-for her and have her afterwards him to woman.

'If anyone deceives a mad unwedded and sleeps with her, he shall repay her and take her as his wife'

Similarly, (14) is in a comparison/contrast relation with the previous utterance; the condition in (13), "gif se hlaford him ponne wif sealde" is contrasted/compared to the similar law regulating the marital status of servants, "gif he wif self hæbbe".

(13) Gif se hlaford him [bonne] wif sealde, sie hio \& hire bearn pæs hlafordes (colawafint,LawAfEl:11.24)

if the lord him then woman gave, be she and her children that lord.

'If the lord then gave him the woman. She and her children will belong to the lord.'

(14) Gif he wif self hoebbe, gange hio ut mid him (colawafint,LawAfEl:11.23)

if he woman self have, go she out with him.

'If he will have the woman himself, she will go with him'

Contrasting the lack of prominence of the pronominal referent he in (14), with the contrastive effect of the DP subject se hlaford in (13), we propose that such DP subjects in $\Sigma \mathrm{P}$ are best analyzed as switch topics, marking a discourse shift. This raises the question what the status is of pronominal objects below pa/ponne, i.e. whether they are found there for discourse reasons or due to some independent structural deficiency.

\subsubsection{Pronouns below $\Sigma \mathrm{P}$}

Although pronouns form perfect topics and in the overwhelming majority of cases occupy $\Sigma \mathrm{P}$, it is possible for a pronoun to occur in the focus area below pa/ponne. The positional discrepancy between OE subject and object pronouns is well-known. That pronominal objects can appear in a variety of positions in the lower clausal domain has been noted by van Kemenade (1987), and especially Koopman (1990), who adduces this fact to question the 'clitic' status of OE pronouns. The main diagnostic for postulating a low position for 
pronouns is the possibility of separation from the subject pronoun, or the possibility of separation between two object pronouns.

Generally speaking, dative pronouns show the strongest tendency towards a low pronoun position, whether they are indirect object pronouns or pronouns stranding P. Also, reflexive pronouns generally prefer to follow their antecedents, but in such cases the sequence in which the pronoun is preceded by a DP subject can be said to be determined by ccommand. A possible explanation for the distribution of indirect object and P-stranding pronouns can be found in the fact that they participate in complex structures and that their presence is required by the structure in which they are found, i.e. double object structure, or a PP structure which can accommodate preposition stranding facts. However, in clauses with focus particles, pronouns following $\mathrm{pa}$ /ponne are relatively restricted to contexts in which $\Sigma \mathrm{P}$ is occupied by the subject pronoun. ${ }^{3}$

(15)a $p a$ [hi] ba [hine] geornlice beheoldon, $p a$ gesawon hi $p a$ dolhswaðe on him, (coeust,LS_8_[Eust]:270.286)

when they then him carefully beheld, then saw they the scars on him 'when they then carefully beheld him, they saw the scars on him'

b Mid py he pa us eac sceawode \& geseah in gewinne \& in ormodnesse gesette beon, ða begde he his cneo to Fæder usses Dryhtnes Hælendes Cristes, (cobede,Bede_5:1.386.8.3839)

With that he then us also watched and saw in distress and in desperation set be, then bowed he his knees to Father our Lord's Saviour's Christ's 'As he watched us also and saw that we were in a position of distress and desperation, he bowed his knees to the Father of our Lord and Saviour Christ...'

We believe that in these sequences the pronominal subject gets the interpretation of switch topic. The joint presence of subject and object pronouns in $\Sigma$ P renders the interpretation of switch topic unavaible to the subject pronoun.

It is not entirely clear what the morphosyntactic status (weak/strong) of the low personal pronoun position is. Its position in the lower clausal domain is variable; the mapping of FocusP material is quite complex, and beyond the scope of this article. However, here we believe that another instance of low pronouns might shed some initial light on the organization of this domain. This context involves sequences in which the complementizer is immediately followed by the focus particle, rendering the area of $\Sigma \mathrm{P}$ empty, with the entire proposition containing the subject pronoun in FocP:

(16)a Gif ðonne ic teala cwæð

(HomS 24.2, 165;van Bergen 2000:92 (11c))

if then I well spoke

"If I spoke well then"

\footnotetext{
3 We have found only one example of a clause with a DP subject in $\mathrm{P}$ and a pronominal object to the right of palponne:

i Gif [min wiif] ðonne [hia] nylle mid clennisse swæ gehaldan, \& hire liofre sie oðer hemed to niomanne, ðonne foen mine megas to ðem londe

if my wife then her not-will in cleanness so keep, and her preferable be other marriage to take, then succeed my kinsmen to the land

'If my wife then does not want to keep herself in cleanness, and prefers to re-marry, then my kinsmen should succeed to the land' (codocu1,Ch_1482_[HarmD_2:15.27)
} 
b Gif ponne [ge lifes bæð forhycgað], ne magon ge ænige pinga lifes hlafe onfon. (cobede,Bede_2:5.112.15.1056)

if then you life's bath reject, not can you any thing's life's loaf receive 'if you despise baptism, you may not in any way receive the bread of life'

In terms of Reinhart (1981), in "empty $\Sigma \mathrm{P}$ " sentences the set of the "Possible Pragmatic Assertions" contains only the bare proposition, without including the relationship between entities and the proposition. This implies that $\Sigma \mathrm{P}$ in such cases is not merged at all. "Empty $\Sigma$ P"' clauses seem to be licensed in one particular context in OE. Consider (17), which in the text precedes (16b):

(17) Gif ge willað onpwegene beon ðy halwendan wellan fulwihtes bæðes, swa eower fæder aðwegen wæs, ponne magon ge eac swylce pæs halgan hlafes dælneomende beon, swa he dælneomende wæs (cobede,Bede_2:5.112.12.1055) if you desire washed be that healing well baptism bath, so-as your father washed was, then can you also in-like-manner that holy loaf sharers be, so-as he sharer was "If you want to be immersed in the healing baptismal font, just as our Father was, then you can also in the same way be sharers of the holy bread, just like he was a breadsharer

If we take a look at the condition expressed in the previous line, "gif ge willad onpwegene beon dy halwendan wellan fulwihtes bæðes", we can see that it is in direct contrast with the condition in the following line. This leads us to the assumption that the reason for placing the whole utterance in the focus domain is to signal contrast with the previous discourse, i.e. what happens if one agrees to accept "baptism bath" and what happens if one refuses it. In other words, $\Sigma \mathrm{P}$ is empty when the full clause is associated with the meaning of contrastive focus.

The same discourse strategy is applied in (18), with a DP subject:

(18)a \& gif se eard sy wynes wæstmbære, sylle man dæghwamlice ælcum breðer fif punda gewihte wines, gif pa unwedru his ne forwyrnað. (cochdrul,ChrodR_1:6.20.162) and if the land be of-wine fruitful, give one daily each brother five weights' weight ofwine, if the storms it not prevent

'if the land is fertile with wine, one should give each brother five weights of wine daily, if the storms do not prevent it.'

b Gif ponne se eard full win næbbe, sylle ma ælcum preo pund wines \& preo pund ealað, \& warnien hi wyð druncen. (cochdrul,ChrodR_1:6.22.163)

if then the land much wine not-have, give rather each three weights of-wine and three weights of-ale, and warn them against drunkness

'if the land then does not have wine, one should rather give each of them three weights of wine and three of ale, and warn them against drunkenness'

It should be noted that the contrastiveness flavor of the focus domain in these cases is greatly contributed by the meaning of the focus particle itself. It remains to be seen what context is needed for "empty $\Sigma$ P" found with other adverbs (cf. van Bergen 2000:91 (11a)).

\subsubsection{DP Subjects in $\Sigma P$}

As evident from Table 2, DP subjects can be found left and right of the adverb: in our terms, in $\Sigma \mathrm{P}$ or in the focus area. It is difficult to define the semantic category of the NPs occupying 
$\Sigma$ P: there seems to be no strict semantic condition on what kind of DP can be construed as topic. However, one clear generalization can be made: while definite DPs are found left and right of the focus particle, indefinite NPs (generic, weakly quantified and bare plural) are preferred in the focus area. In such cases, $\Sigma$ P hosts the personal pronoun object only (20), or remains empty, yielding the sequence complementizer-adverb (21).

(20)a Gif hine ponne [yfel mon] hæfð, ponne bið he yfel purh pæs monnes yfel pe him yfel mid deð, \& purh dioful (coboeth,Bo:16.38.26.702)

if him then evil man has, then be he evil through the man's evil who him evil with does and through devil

"if an evil person then has him, then he is evil through the evil of the person who does evil with him, and through the devil"

b Mid by [hine] pa [nænig mon] ne gehabban ne gebindan meahte, $b a$ orn sum pegn (cobede,Bede_3:9.184.27.1847)

when him then no man not capture not tie-up, then ran some servent

'when no one then could not capture him and tie him up, then a servent pursued him'

(21)a Gif ponne [swiðra wind] aras, ponne tynde he his bec(cobede,Bede_4:3.268.18.2727) if then stronger wind arose, then closed he his books?

'if stronger wind then arose, then he closed his books'

b Gif ponne [hwylc læsse ping] sie to smeagenne, ponne hæbbe he para yldestra

manna gepeaht (cobenrul,BenR:3.16.9.232)

if then any less thing be to think on then have he the oldest men's advice

'if a lesser thing then has to be decided, he will take advice among the oldest men

This tendency of OE indefinites seems to support the semantic partition of a sentence into the presuppositional and 'novel' part, i.e. restrictive clause and nuclear scope (in the sense of Heim 1982, 1983 and Diesing 1992). Therefore, we might assume that a mapping principle associating nominal expressions in particular syntactic positions with particular types of interpretation is operative in $\mathrm{OE}$. Here we would like to point out that the situation in $\mathrm{OE}$ does not necessarily imply a one-to-one correspondence between 'indefiniteness' and 'nonpresuppositional interpretation'; the lack of indefinite subjects in $\Sigma \mathrm{P}$, i.e. strong/ presuppositional indefinite NPs, could be accidental. What is problematic, though, is that the Mapping Hypothesis predicts that all low subjects are interpreted as within the nuclear scope, respecting the 'novelty condition'. The presence of strong/ presuppositional definite subjects in the low position quite clearly shows that a purely semantic account cannot account for the different subject positioning in OE either. Furthermore, it is not certain whether or not we can associate the lower subject position with the v/VP internal "base" position, where existential closure applies and gives rise to a weak interpretation; lower subjects can be found both preceding and following low (manner) adverbs/adverbials which strongly point to the fact that the structure of the "focus" area is much more complex than what we seem to suggest with our relatively simple division.

(22) a. Gif him ðonne God ryhtlice and stræclice deman wile (cocura, CP:5.45.20) if him then God rightly and strictly judge will 'If God then wishes to judge him justly and strictly'

b. Gif ðonne unwcerlice [sio lar] toflewð ðurh oferspræce (cocura,CP:15.97.9.636) if then unwarily the teaching flees-away through excessive-speaking "if the teaching then unwarily disperses through excessive speaking" 
That we are indeed dealing with two distinct positions for the DP subject can be seen from two types of contexts in which both positions seem to be filled. The first one involves coordinate subjects, the second one appositive subjects. OE allows discontinuous elements and $\mathrm{OE}$ coordinate structures allow non-adjacency of the conjuncts. Although the second conjunct can be found in a variety of positions, it seems to occupy the lower DP subject position cases like (23):

(23) pa [se Wisdom] pa [\& seo Gesceadwisnes] pis leoð asungen hæfdon, pa ongan he eft sprecan (coboeth,Bo:3.9.15.106) when the wisdom then and the Reason this song sung had, then began he again speak 'when Wisdom and Reason then had sung this song, then he began to speak again'

\subsubsection{Demonstrative pronouns as subjects}

Weak demonstrative subjects seem to show a distribution similar to DP subjects. They can be found both in $\Sigma$ P (24) and in FocP (25).

(24) Gyf se ponne berste, nime ponne leafe ... (colaw2cn,LawIICn:19.2.54) if that then fails, take then permission ... 'if that one then fails, then he should take permission'

(25) Gif hire ðonne se wiðsace ((cocura,CP:5.45.2.249); Bergen 2000:109; (35a)) if her then he (that one) refuse "if he then refuses her"

Van Bergen (2000: 116) offers a statistical account of the distribution of various types of subjects with respect to the adverb ponne in conditional subordinate clauses introduced by gif. Of the demonstrative subjects, she has considered the masculine singular "se", which in 7 out 10 instances precedes ponne. We believe, that the relative preference of demonstrative subjects (and as we will later see, demonstrative objects as well) in $\Sigma$ P is due to their special status. Contra Pintzuk (1993), we do not assume that they are pronominal, but rather follow Cardinaletti and Starke (1999b; Responses) in assuming that certain demonstratives belong to a separate category - neither demonstrative nor personal pronoun. Weak demonstratives in $\mathrm{OE}$ are anaphoric elements, and in that they closely resemble pronouns and qualify as $\Sigma \mathrm{P}$ material. However, unlike personal pronouns, instead of identifying or making a direct connection with the referent, weak demonstratives are licensed by referring to a certain property of the referent. We believe that this extra "information" import is responsible for their rather frequent patterning with nominal elements.

\subsubsection{Indefinite subjects in $\Sigma P$}

As we said earlier, indefinite expressions are not impossible as topics, and the tendency for indefinite DP subjects to be low may be coincidental, in view of the fact that indefinite pronouns, such as $h w a$ 'whoever' (26) and aenig 'any' (27), may occur in $\Sigma$ P. The same holds for the so-called indefinite pronoun mon in (28).

(26) Gif [hwa] ðonne of giernesse \& gewealdes ofslea his pone nehstan purh searwa (colawafint,LawAfEl:13.37)

If any then out of importunity and of his own will slay his the nearest through treachery

'if any then importunely and willingly kills his next of kin through treachery' 
(27) \& gif ænig ponne sy up ahafen \& swa swiðe gredig pissere worulde

(Ch 1232.11; Bergen 2000:119; (53a))

and if any then be up lifted and very greedy of-this-world

'and if anyone then is arrogant and so coveous of this world'

(28) \& gif mon ponne ne mihte hi to rihte gecyrron (coblick,HomS_14_[BlHom_4]:45.120.575)

and if one then not might them to justice/equity turn

'if one might then turn them to justice'

However, while indefinite pronouns such as $h w a$ and aenig, which are most usually found to the right of the adverb in the low position, man seems to be exclusively found in a high position, $\Sigma$ P in our terms. This fact has been noted by van Bergen (2000), who shows that in the rather small number of cases of man in subordinate clauses, man always precedes ponne. Considering the "indefinite" semantics man is commonly associated with, this is highly surprising. Furthermore, man can quite actively combine with personal pronoun objects in $\Sigma$ P.As we saw in Table 4 , it precedes the pronominal object in 1 case, and it follows the pronominal object in 6 cases.

... on ðam ðe him mon ðonne bebeodeð (CP 6.47.17; van Bergen 2000:108; (34a)) on that that him one then offers

"...in that which is offered to him"

ac mid pancgunge \& mid glædnysse underfon pæt [man] [him] ponne don mage, (cochdrul,ChrodR_1:6.32.169)

but with gratitude and with gladness receive what MAN them then do may

'but with gratitude and with gladness received what one then may do for them'

A possible approach to these facts could be that predicates with man subjects get an impersonal interpretation; since the key feature of impersonals is the "saturation" of the external argument (cf. Reinhart 2000, and Marelj 2004), by assigning an ARB-index with the properties [-referential] and [+human]. We believe this to be crucial for man's special syntactic behaviour. This hypothesis is further supported by the fact that when the same man is found in a quantified structure, i.e. hwylc man 'whichever', naenig man 'not-any', aenig mon 'anyone', it loses its special properties and behaves like a regular nominal expression. This does not seem to be exclusively due to some structural property of man, e.g. lack of internal structure as with personal pronouns. A personal pronoun subject never shows any variation with pronominal objects - it always precedes them. Although man seems to be sensitive to discourse considerations when combined with a personal pronoun, we believe that in such cases it is the pronoun that changes positions; when its referent is rendered less prominent in the discourse than required for its placement in the highest position, it surfaces lower, following "man". In other words, man is always in the same position, it is the position of the pronoun that is sensitive to discourse.

\subsubsection{DP objects in $\Sigma P$}

DPobjects can occur in $\Sigma \mathrm{P}$ alone or in combination with a subject. When a DPsubject and a DPobject together precede $p a /$ /bonne, the subject always precedes the object.

\begin{tabular}{|l|c|}
\hline DPsubject - DPobject - pa/bonne & 11 \\
\hline Prosubject - DPobject - pa/ponne & 22 \\
\hline DPobject - DPsubject - pa/ponne & 0 \\
\hline
\end{tabular}


Let us first consider the cases in which the DPobject alone precedes the particle: these are mostly cases like (30), in which the subject consists of a single demonstrative pronoun. This dataset has, in the overwhelming number of cases the neuter accusative demonstrative Paet as the object left of $\mathrm{pa} /$ /ponne, which is then either anaphoric or cataphoric to an event in the previous or following context, often expressed by a that-clause. Here are some examples

(30) pa [pæt] pa Porsenna gehierde, he ðæt setl \& pæt gewin mid ealle forlet, pe he ær preo winter dreogende wæs.

(coorosiu,Or_2:3.41.9.778)

when that then Porsenna heard, he the siege and the fight with all left, which he before three winters conducting was

'when Porsenna heard that, he immediately withdrew from the war he had been engaged in for three years.'

The demonstrative pronoun here is neuter accusative paet, referring back to an event in the previous discourse; it does not have an individual as its referent. Paet here can also be cataphoric, as in the following context:

(33) pa [ðæt] pa Wulfhere se cyning onget, \& him gebodad wæs, pæt in pære mægðe Eastseaxna of dæle Cristes geleafa aidlad wære, pa sende he Gearaman pone biscop, se wæs Trumheres æfterfylgend, in pa mægðe Eastseaxna to gereccenne pone gedwolan, \& heo to soðfæstnesse geleafan eft gecegan. (cobede,Bede_3:22.250.17.2554)

when that then Wulfhere the king heard, and him announced was, that in the province of-East Saxons' of part of Christ's faith emptied were, then sent he Jaruman the bishop, who was Trumhere's successor, in the tribe of East Saxons to correct that error, and her to true faith again call

'when the king Wulfhere heard that, and it was announced to him, that the faith in the East Saxon province was partly profaned, then he sent Bishop Jaruman to correct that error and restore the tribe to the true faith'

\subsubsection{Discussion}

We saw in the previous section that if we make the assumption that the position of $p a /$ /ponne is fixed and has the status of a focus particle, we get a novel view of the organization of the clause in which syntactic factors and discourse factors are closely interwoven.. The $\Sigma$ P area left of the focus marker is in very many cases quite simple and straightforward; subject pronouns are in that position in an impressive 1250 cases. At a rather lower rate, the organization of this area may be more complex, as the figures in Tables 4 and 5 show. We have discussed possible generalizations that may be formulated with respect to how discourse relations determine the order of material within $\Sigma \mathrm{P}$; one generalization is that personal pronouns, if they are assumed to reflect continued topics in discourse terms, are positioned within $\Sigma$ P according to the prominence of their discourse referent. Other material such as a DP subject or DP object may take precedence over the pronoun within $\Sigma$ P and in that case they are interpreted as switch topics. A further generalization is that in the $\Sigma \mathrm{P}$ area, indefinite DP-subjects are rare, and we have made some tentative suggestions for the exceptions to this generalization. One trait that is shared by $\Sigma \mathrm{P}$ material then is that it shows a strong tendency towards being definite and specific, including definite DP's, personal pronouns which have a 
discourse referent, and demonstrative pronouns which are inherently definite and which in the cases we have discussed have a highly prominent discourse referent. We have also hypothesized that the cases in which the $\Sigma \mathrm{P}$ area is complex in Old English reflect a language stage where clausal organization was more paratactic, i.e. a stage where the distinction between main clause and subclause had emerged less clearly than by late Old English times. Let us now turn to Middle English.

\section{Middle English}

The transition to Middle English marks a sharp contrast in several respects. The first contrast is that the use of $p a$ and ponne becomes a good deal less frequent in absolute numbers. Where the search file in Old English contains some 2500 instances, the Middle English one includes 177. ${ }^{4}$ This in itself might indicate that $\mathrm{pa} /$ ponne were in the process of loosing their discourse marking properties, as it might suggest that the properties of $\mathrm{pa}$ /ponne were no longer represented robustly enough for the learner/speaker/writer to recognize the discourse system. But there are several further arguments as well. Within this dataset for Middle English, it is clear that in comparison to Old English, the $\Sigma \mathrm{P}$ area has been drastically simplified, as evident from the following tables:

\begin{tabular}{|l|c|}
\hline & Nonroot clauses \\
\hline DP subject follows $p a /$ ponne & 5 \\
\hline DPsubject precedes $p a /$ ponne & 23 \\
\hline
\end{tabular}

Table 6 Pa/ponne andDP subject in Middle English

Table 6 shows that the relative number of DP subjects appearing on the left of DP has increased considerably since Old English times. DP subjects found on the left of pa/ponne include all the types discussed for Old English above (two examples are given in (34), but also indefinite subjects other than hwa or man, as in (35):

(34)a pt ænig hæfde pa geðincðe, pt heo mihte mæden beon \& eac cildes moder.

(CMKENTHO,135.54)

that any had then thought that she might maiden be and also child's mother "that any then had thought that she might be a maiden as well as a child's mother"

b where Seynt Basilie was po bishopp. $\quad$ (CMROYAL,260.370) where St. Basil was then bishop 'where St. Basil was bishop then'

(35) patt twe33enn burr3hess wærenn pa / pa Crist comm her to manne,/ An i be land off Galile / I Zabuloness mæ33pe, / An operr i Juda nohht ferr / Fra 3errsalæmess chesstre, (CMORM,I,242)

That two citizens were then /when Christ came here to people in the land of Galilee/in the Zabulon's country/another in Juda not far from Jerusalem's city, 'that there were then two citizens, when Christ came here to the people in the land of Galilee, in Zebulon's country, another in Judea, not far from the city of Jerusalem'

\begin{tabular}{|l|l|}
\hline & Nonroot clauses \\
\hline Pro subject preceding pa/ponne & 51 \\
\hline
\end{tabular}

\footnotetext{
${ }^{4}$ Spelling variants searched for are: pa, panne, pan, po, poo, penne.
} 


\begin{tabular}{|l|l|}
\hline Pro subject following $\mathrm{pa/ponne}$ & 0 \\
\hline
\end{tabular}

Table 7 Da/ponne and pronominal subject in Middle English

Table 7 shows that the position of subject pronouns with respect to the adverb remains constant as compared to Old English.

\begin{tabular}{|l|l|}
\hline & Nonroot clauses \\
\hline Pro obj - pa/ponne-DP-subj & 0 \\
\hline Pro obj - DP-subj - pa/ponne & 0 \\
\hline Pro subj - pro obj - pa/ponne & 1 \\
\hline DP subj - pro obj - pa/ponne & 1 \\
\hline Total pro object - pa/ponne & 2 \\
\hline
\end{tabular}

Table 8: pa/ponne and pro object in Middle English

Table 8 shows up a significant change compared to the Old English situation. There isn't a single example of an object pronoun in the highest position in $\Sigma$ P. The two examples of an object pronoun following a pronominal subject and a DP subject respectively:

(36) \& tatt peod wass hæpene peod / patt Crist 3aff pa swillc takenn; / Forrpi patt he pe33m wollde pa / To rihhte læfe wendenn. (CMORM,I,118.1027) that people was heathen people / which Christ gave then such sign / because that he them wanted then / the true faith lead

'they were heathen people, whom Christ gave such a sign, because he wanted to lead them to the true faith'

(37) Swa summ be Romanisshe king / Itt haffde panne dæledd, (CMORM,I,289.2393)

As the Roman king / it had then divided

'As the Roman king then had it divided'

Likewise, there are two cases in which a DP object is found following the subject in $\Sigma \mathrm{P}$ :

(38)a \& 3ho wass pa swa winntredd wif / \& off swa mikell elde, / patt naffde 3ho nan kinde pa / Onn hire forr to tæmenn.(CMORM,I,13.225)

and she was then such aged woman/ and of such great age/that not-had she no kindred then / in her to bring forth

'and she was then of such an age that she could not bring forth any kindred'

b bt tu pi mis-bileaue lete penne, lanhure, \& lihte to ure. (CMKATHE,31.191) that you your unbelief leave then, at least, and descend to ours 'that thou wilt then, at least, forsake thy unbelief and descend to ours [our faith]'

Note that all examples are from the relatively early Ormulum. ${ }^{5}$ The figures show then that in

\footnotetext{
${ }^{5}$ There is further and rather unusual pattern in Ormulum, in which pa/ponne is in clause-final position, following the object and even the nonfinite verb. An example is:

i \& te33 patt haffdenn lare inoh / Off patt he comenn shollde, / Nærenn nohht warre off patt, tatt he / Wass cumenn $\boldsymbol{p a}$ to manne. (CMORM,I,252.2054)

and they who had teaching enough / of that he come should / not-were not aware of that he / was come then to man

'and those who knew enough doctrine to know he was to come, were not aware of his coming to man then'
}

It seems to us that these are case of genuine temporal use of the adverb. We leave this matter for further research. 
Middle English, the $\Sigma \mathrm{P}$ area has become virtually restricted to the subject pronoun or DP. One interesting qualification that should be made here is that in a good number of cases (14 out of 51 for pronominal subjects, and 13 out of 23 for DP subjects), we find the pattern: Subjectfinite verb-pa/ponne.

We interpret this development as a final straightening out of the left periphery of the subclause to a fixed SVO order with a relatively straightforward functional structure in which the subject is licensed in a specifier position whose head attracts the finite verb. We should emphasize here that this is how we would characterize the Old English subclause - clearly the topic area in the main clause remains relatively articulate until at least the end of the Middle English period; we leave the details of this for further research, but note that this accounts for the often-made observation that in some respects, the subclause is more innovative than the main clause. As noted in section 2, Nilsen (2003) assumes that $\Sigma P$ in the Germanic languages is unmarked, i.e. it is not associated with topic-hood. While assuming Nilsen's general framework, we departed from this assumption for Old English: if pronouns are interpreted as continued topics and pa/ponne as a focus particle, then the distribution of material on the left of the adverb and in particular the positional asymmetry between pronominal subjects and DP subjects in the Old English subclause shows its $\Sigma \mathrm{P}$ is marked. We have speculated that this situation is inherited from earlier stages in which the main clause/subclause distinction was not as clearcut and clearly encoded as it came to be in the course of the Middle English period. We may then interpret the development from Old English to Middle English in Nilsen's terms as one from marked to unmarked $\Sigma \mathrm{P}$, and as a spin-off of the establishment of hypotaxis. In analytical terms, this transition looks similar to what Biberauer and Roberts assume for the development from Old to Middle English: in Old English a whole constituent is pied-piped to Spec,TP, while in Middle English, the DP subject alone comes to be licensed there. Observe, however, that the analysis in terms of pied piping presented by Biberauer and Roberts should be regarded as coexistent with a relatively complex topic domain as we have analysed it here: their analysis has nothing to say about the distribution of any material higher than the DP-subject.

Our material shows that the topic domain in the Old English subclause develops into what may be characterized as the subject domain in Middle English. The question remains why this happened. Let us begin by pointing out that subjects did occur in $\Sigma \mathrm{P}$ in Old English: Pronominal subject occur there virtually always, DP subject in some $40 \%$ of the cases.

Subjects were therefore robustly represented in this portion of the clause. But their occurrence there is triggered by discourse considerations and is strongly associated with definiteness/ specificity of the subject, as discussed above. The figures in Table 6 show that DP subjects, whatever their character (definite/indefinite/impersonal...), encroach upon this area to some $80 \%$ in Middle English, and this happens early in the period. We suggest, therefore, that the characteristics associated with topic-hood in $\Sigma \mathrm{P}$ : definiteness/specificity, switch topic status, prominence of discourse referent, no longer provided the crucial clue for appearance in this area of the clause. Possibly, this development may be related to the substantial loss of morphology to mark the definiteness/specificity of a DP. Observe in this connection that the case paradigm for demonstrative pronouns was lost relatively early in Middle English, and that likewise the separate adjective declensions for definite and non-definite DP's were drastically simplified, resulting in considerable loss of definiteness marking (Lass 1992). Further research will have to show whether this correlation can be upheld.

\section{References:}


Alexiadou, Artemis (2004) Adverbs across frameworks. Lingua 114/6, 677-682.

Bergen, Linda van (2000) Pronouns and Word Order in Old English, with Particular Reference to the Indefinite Pronoun Man. Unpubl. Dissertation, U. of Manchester.

Biberauer and Roberts (forthcoming) Changing EPP parameters in the history of English: accounting for variation and change. To appear in English Language and Linguistics.

Cardinaletti, Anna \& Michal Starke. (1999a). The typology of structural deficiency: A case study of the three classes of pronouns. In H. van Riemsdijk (ed.) Clitics in the Languages of Europe, 145-234. Berlin: Walter de Gruyter.

Cardinaletti, Anna, and Michal Starke (1999b) Responses and demonstratives. The typology of structural deficiency. In H. van Riemsdijk (ed.) Clitics in the Languages of Europe, 273-290. Berlin and New York: Mouton de Gruyter.

Cinque, Giuliamo (2004) Issues in adverbial syntax. Lingua 114/6, 683-710.

Diesing, Molly (1992) Indefinites, MIT Press, Cambridge, Massachusetts.

Ernst, Thomas (2004) Principles of adverbial distribution in the lower clause. Lingua 114/6, 677-682.

Fischer, Olga, Kemenade, Ans van, Willem Koopman, Wim van der Wurff: The Syntax of early English. Cambridge University Press.

Grohmann, Kleanthes K. (1997) Pronouns and the left periphery of West Germanic embedded clauses. In W. Abraham \& E. van Gelderen (eds.) German: Syntactic Problems-Problematic Syntax, 163-189. Tübingen: Niemeyer.

Grohmann, Kleanthes K. (2000) Towards a syntactic understanding of prosodically reduced pronouns. Theoretical Linguistics 26.3, 175-210.

Haeberli, Eric (2000) Adjuncts and the syntax of subjects in Old and Middle English. In Pintzuk, Tsoulas and Warner (eds) Diachronic Syntax: Models and Mechanisms. Oxford: Oxford University Press 109-121

Haeberli, Eric and Richard Ingham (2004) The position of negation and adverbs in early Middle English. Paper presented at the $2^{\text {nd }}$ York-Holland Symposium on English historical syntax. Leiden.

Heim, Irene (1982) The Semantics of Definite and Indefinite Noun Phrases. Doctoral Dissertation. University of Massachusetts at Amherst.

Heim, Irene (1983) File change semantics and the familiarity theory of definiteness. In R. Bäuerle, C. Schwartze and A. v. Stechow (eds.) Meaning, Use and Interpretation of Language, de Gruyter, Berlin, 164-189.

Hoop, Helen de. (1992) Case Configuration and Noun Phrase Interpretation. Doctoral Dissertation. University of Groningen.

Jäger, Gerhard (1995) Weak Quantifiers and Information Structure. In J. N. Beckman (ed.), NELS 25. Proceedings of the North East Linguistic Society 1, 303-318, GLSA, Amherst.

Kato, Kozo. 1995. "The interjection la and subject pronouns in Old English". In H. Nakano (ed.) Linguistics and Philology. Kogaka Shuppan, 23-40.

Kiss (1995) Discourse Configurational Languages. Oxford: Oxford University Press.

Kayne, Richard (1998) Overt vs. Covert Movement. Syntax 1:128-191

Kemenade, Ans van (1987) Syntactic Case and Morphological Case in the History of English, Dordrecht:Foris.

Kemenade, Ans van (2002) 'Word order in Old English Prose and Poetry: the position of finite verbs and adverbs'. Donka Minkova and Robert Stockwell (eds.) Studies in the History of the English Language: A Millennial Perspective. Berlin: Mouton de Gruyter, 355-373.

Koopman, Willem (1990) Word Order in Old English. Doctoral dissertation, University of 
Amsterdam.

Krifka, Manfred (1992) A compositional semantics for multiple focus constructions. In J.Jacobs (ed.) Informationsstruktur und Grammatik (Linguistische Berichte, Sonderheft 4).

Laenzlinger, Christopher (1998) Comparative Studies in Word Order Variation: Adverbs, Pronouns and Clause Structure in Romance and Germanic. Amsterdam: John Benjamins.

Laenzlinger, Christopher \& Ur Shlonsky (1997) Weak pronouns as LF-clitics: clustering and adjacency effects in the pronominal systems of German and Hebrew. Studia Linguistica 51.154-185.

Marelj, Marijana (2004) Middles and Argument Structure across Languages. Doctoral Dissertation. Utrecht University.

Nilsen, Øystein (2003) Eliminating positions. Doctoral Dissertation, Utrecht University.

Nilsen, Øystein (2004) Domains for adverbs. Lingua 114/6, 801-847.

Oshima, David Y. (2003) Contrastive topic as a paradigmatic operator. Workshop on Information Structure in Context, Stuttgart University: November 15-16, 2002. (draft of the paper available at http://www.stanford.edu/ davidyo/publications)

Reihnart, Tanya (1981) Pragmatics and linguistics: an analysis of sentence topics, Philosophica 27/1, 53-94.

Reinhart, Tanya (2000), The Theta System: Syntactic realization of verbal concepts, OTS orking papers, 00.0/TL (available also at http://www.let.uu.nl/ tanya.reinhart)

Reinhart, Tanya (2004) Topics and the Conceptual Interface. In H. Kampt and B. Partee (eds.) Context Dependence in the Analysis of Linguistic Meaning, Amsterdam: Elsevier Press, p.275-305.

Rizzi, Luiggi. (1997). The fine structure of the left periphery. In L. Haegeman (ed.), Elements of grammar: A handbook of generative syntax. Dordrecht: Kluwer.

Taylor, A. et al. (2003) The York Corpus of Old English Teaxts. Available from the Oxford Text Archive. 